\title{
Hinge Conditions: An Argument Against Skepticism
}

by Blake Barbour

\section{Introduction}

The purpose of this paper is to introduce the problem of skepticism as the Transmissibility Argument represents it and to explore different avenues for overcoming the argument for skepticism. The fallibilist's response to skepticism will be briefly explored, along with the skeptic's counterargument to fallibilism. The main focus of the paper will be on Wittgenstein's concept of Hinge Propositions; however, this will be supplemented by Dretske's idea that the communication channels through which knowledge can be gained have built in channel conditions. By the end of this paper, I will have put forth the notion that the existence of Hinge Conditions may be a possible solution to skepticism.

\section{External World Skepticism}

Skepticism about the external world is characterized by the belief that the world outside of your own mind (i.e. other minds and the external physical world) cannot be proven to exist. Or, as explained by Richard Feldman, "the issue raised by skepticism is largely about whether the reasons we have for our ordinary beliefs are good enough to yield knowledge" (2003, p. 108). In other words, even if there is an 
external world, we cannot gain knowledge of the external world if skepticism is true. On the surface, skepticism appears to be easily refutable; certainly, it seems as if I can appeal to my sensory perceptions in order to gather information about the external world. Following my experience of the world around me through sight, sound, taste, touch, and smell, I would naturally be able to gain knowledge of the external world based on my experiences. For example, say that I see a bird in front of me. It seems natural that after I visually experience the sight of a bird, I would gain the knowledge that the bird exists based on my visual experience. However, the argument for skepticism is not so easily ignored.

What if I am unknowingly at the mercy of a demon that is simply deceiving my senses ${ }^{1}$ into having the visual experience of a bird, causing my belief that I formed of the existence of the bird on the basis of that experience to be false? Or, what if I am simply a brain in a vat that is receiving the correct stimulus such that the above deception is the same? Now the issue of skepticism does not seem so easily dismissed. The following is an example of an argument for skepticism:

The Transmissibility Argument for Skepticism:

p: Some ordinary proposition (I have hands.)

not-sk: The denial of some skeptical proposition (I am not a bodiless brain in a vat.)

\footnotetext{
${ }^{1}$ Descartes originally brought this concern forth.
} 
(P1): If you can know that $p$, and you know that $p$ entails not-sk, then you can know that not-sk.

(P2): You know that p entails not-sk.

(P3): You can't know that not-sk.

(C): You can't know p.

If the above example's reasoning is taken as true, then the skeptic is proven correct, and we should immediately deny all knowledge of the external world. However, at first glance, there appears to be a simple way to sidestep the Transmissibility Argument by denying that knowledge requires certainty.

\section{Fallibilist Response to Skepticism}

According to Feldman, fallibilism can be utilized as a successful argument against skepticism given that it expresses the belief that knowledge does not require absolute certainty, but merely needs very good reasons (2003, p. 122). For a fallibilist, your visual experience, assuming proper lightening and good eyesight, as of $\mathrm{p}$ is a good reason $\mathrm{r}$ for you to form the true belief that $\mathrm{p}$; thus, you gain knowledge that $\mathrm{p}$. Also, according to fallibilism, if $\mathrm{r}$ is a reason to believe $\mathrm{p}$, and $\mathrm{p}$ entails not-sk, then $r$ is a reason to believe not-sk ${ }^{2}$. So, if the fallibilist argument can be taken as true, then (P3) and (C) of the Transmissibility Argument are false, and

\footnotetext{
2 This is called a transmission of reason and will be looked at in more depth later.
} 
skepticism is not a valid concern. Unfortunately for fallibilists, the skeptic has quite a strong objection to the fallibilists' methodology:

Objection to Fallibilism:

(1) p entails not-sk, so the $\operatorname{Pr}(\mathrm{p})<\operatorname{Pr}($ not-sk) and the $\operatorname{Pr}(\mathrm{p} \mid \mathrm{r})<\operatorname{Pr}($ not-sk $\mid \mathrm{r})$.

(2) sk entails r, so $\operatorname{Pr}($ sk $\mid r)>\operatorname{Pr}($ sk), and the $\operatorname{Pr}($ not-sk $\mid r)<\operatorname{Pr}($ not-sk).

(3) Following the above reasoning, if $r$ made you know $p$, then you had to have already known not-sk.

(4) But how could you have already known not-sk?

The above example shows that if you have the same reasons for $\mathrm{p}$ and not-sk, those reasons lower the probability for not-sk while raising the probability for $\mathrm{p}$. However, the probability for not-sk, given reasons $r$, should always be higher than the probability for $\mathrm{p}$ given reasons $\mathrm{r}$. So, if $\mathrm{r}$ raises the probability for $\mathrm{p}$ enough that you know p, then you must have already known not-sk because, as stated previously, $\operatorname{Pr}($ not-sk $\mid r)>\operatorname{Pr}(p \mid r)$. This is a strong argument, as fallibilism supports the idea that your knowledge of not-sk is earned by way of empirical evidence, and yet, the above example seems to contradict this. In fact, it appears that fallibilism supports the idea that you have a priori ${ }^{3}$ knowledge of not-sk. This contradiction appears to undermine the fallibilist argument, and as such, we must turn to other antiskeptical appeals in order to dismiss the Transmissibility Argument.

${ }^{3}$ A priori knowledge is knowledge that is independent of experience. 


\section{Language Games and Hinge Propositions}

In his book On Certainty, Wittgenstein looks to solve the problem of skepticism by taking a close look at what he calls language-games ${ }^{4}$. These language-games contain indubitable propositions ${ }^{5}$ that act as the hinges upon which our questions, assertions, and doubts about the world around us turn (1969, p. 44) ${ }^{6}$. Wittgenstein asserts that these propositions cannot be doubted because doubts require grounds, which in turn require certainties (i.e. Hinge Propositions). If Hinge Propositions were to be called into doubt, then the whole framework of language would be called into doubt, in which case the meanings of words would be called into doubt; thus, the doubts themselves would no longer have any clear meaning. But, how is it that these doubts actually lose their meanings? If I say that "I doubt that I have hands," do my words suddenly lose their meaning?

According to Wittgenstein, your knowledge of Hinge Propositions is not earned by way of empirical evidence, but rather a person should always be rationally certain of Hinge Propositions in keeping with the rules of the language-game. The proposition that I have two hands is a Hinge Proposition? 7 and as such, I should always be rationally certain that I have two hands. Yet, while I am certain of having

\footnotetext{
4 According to Wittgenstein, a language-game can be considered as a "whole, consisting of language and the activities into which it is woven" (2009, p. 8).

${ }^{5}$ Indubitable propositions may be true or false, but they are exempt from doubt.

6 These indubitable propositions will henceforth be known as Hinge Propositions.

7 It is important to note that Wittgenstein does not regard the proposition I have hands as an ordinary proposition, as it is put forth in the Transmissibility Argument.
} 
two hands (under normal circumstances), I cannot assert this aloud. I cannot say, "I know I have two hands," because that would be violating the rules of the languagegame. I have two hands is a knowledge claim that I must be rationally certain of, but it is one which is not suitable for assertion. This is because within a languagegame the reason for asserting a knowledge claim is in order to answer doubts on the matter. So, in asserting that "I know I have two hands," I am opening the matter to be rationally doubted. However, the rules of the language game state that the proposition I have two hands is a Hinge Proposition, and as such, it is not open to doubt. In effect, the reason that Hinge Propositions cannot be asserted is "because of the certainty that attaches to our beliefs in these propositions" (2006, p. 3). According to Wittgenstein, any reason for a doubt or belief in a claim "must be more certain than the proposition claimed as known" (2006, p. 3). This shows that since Hinge Propositions are that of which we are most certain, there can be no reasons or doubts asserted for or against them. Wittgenstein's argument on the structure of reasons can be seen as follows 8 :

(P1): All rational doubts are grounded in reasons.

(P2): In order for reason $r$ to count as a rational ground for S's doubt in the proposition $\mathrm{p}$, it must be more certain for $\mathrm{S}$ that $\mathrm{r}$ than $\mathrm{p}$.

(C1): So, those propositions which are most certain cannot be rationally doubted.

\footnotetext{
8 This example is taken from Duncan Pritchard's paper "Epistemic Relativism, Epistemic Incommensurability, and Wittgensteinian Epistemology."
} 
(P3): All rational belief is grounded in reasons.

(P4): In order for reason $r$ to count as a rational ground for S's belief in the proposition $\mathrm{p}$, it must be more certain for $\mathrm{S}$ that $\mathrm{r}$ than $\mathrm{p}$.

(C2): So, those propositions which are most certain cannot be rationally believed.

(P5): But all belief-systems must include propositions which are held to be optimally certain.

(C3): So, one's belief-system requires the existence of propositions-hinge proposition-which one's commitment to, while optimally certain, is immune to rational doubt or rational support.

One might try to skirt around Wittgenstein's structure of reasons regarding Hinge Propositions by appealing to the Transmission Principle, which states that reasons can transmit across the entailment from one proposition to another, but that attempt would end in failure. While the Transmission Principle works fine in many cases when only dealing with ordinary propositions, it fails when the entailed proposition is a Hinge Proposition. The Transmission Principle can be laid out as follows:

The Transmission Principle:

If $r$ is a reason to believe $p$, and $p$ entails $q$, then $r$ is a reason to believe $q$. 
One can clearly see how the Transmission Principle fails when the entailed proposition is a Hinge Proposition in the following example:

r: It appears to me visually as if the wall is red.

h1: The wall is red.

h2: the wall isn't a cleverly disguised white wall. (Hinge Proposition)

The above example can be laid out in the following format: $r$ is defeasible evidence for h1; h1 entails h2; $r$ is not defeasible evidence for $h 2$. The reason $r$ is not defeasible evidence for $\mathrm{h} 2$ is because $\mathrm{h} 2$ is background information that must be in place in order for $r$ to be evidence for $h 1$. As such, $r$ is evidence for $h 1$ by virtue of the fact that you are already justified in believing $\mathrm{h} 2$; thus, $\mathrm{r}$ cannot be a way of coming to know $\mathrm{h} 2$ because $\mathrm{h} 2$ is already known.

Wittgenstein is of the mind that reasons do not transmit across entailment when the entailed proposition is a Hinge Proposition. This means that coming to learn a non-Hinge Proposition is not a way of coming to learn a Hinge Proposition. However, while Wittgenstein rejects the Transmission Principle, he accepts closure. That is, Wittgenstein believes that if you are certain of a non-Hinge Proposition, then you should be certain of any Hinge Proposition entailed by that non-Hinge Proposition. Closure can be laid out as follows: 
Closure Principle:

If you know $p$, and p entails $q$, and you competently deduce $q$ from $p$, then you know q.

An example of the closure principle is "that if [you] know that Napoleon won the battle of Austerlitz in 1805, and you competently deduce on this basis that the universe did not come into existence five minutes ago, then you also know the entailed proposition" (2012, p. 261-262). If the Closure Principle is true, then that means that you can claim to know a Hinge Proposition by way of competently deducing it from an ordinary proposition, as seen above. However, if the Hinge Proposition can be classified as knowledge, then it can be doubted, as it is not clear that the doubting of a Hinge Proposition actually renders words meaningless. This is because, according to Wittgenstein, Hinge Propositions are consequences of the rules of the language-game rather than actual rules themselves; thus, you could merely interpret the language-game's rules differently, allowing yourself to doubt the existence of Hinge Propositions. So, the only way to protect a Hinge Proposition from all forms of doubt is to assert that a Hinge Proposition is unknowable. This seems plausible given that while Wittgenstein calls Hinge Propositions "propositions," they are actually closer to conditions that must be in place for knowledge to be acquired. Following this interpretation of Hinge Propositions, they are not really propositions at all in that they cannot ever be known, but rather they are a part of the framework, or rules, of the language-game envisioned by Wittgenstein. 
Wittgenstein himself may have had this in mind as he wrote the following: “Giving grounds [...] comes to an end;--but the end is not certain propositions' striking us immediately as true, i.e. it is not a kind of seeing on our part; it is our acting, which lies at the bottom of language-games" (2006, p. 14). Wittgenstein also said that our certainty in Hinge Propositions "lies beyond being justified or unjustified: as it were, as something animal" (1969, p. 47). This "animal action" is the heart of the language-game (i.e. the ultimate ground of the language-game). The certainty that we have for Hinge Propositions is not some form of rational certainty but rather a type of instinct or pragmatic way of acting required for knowledge. As such, it would be more appropriate to call Hinge Propositions Hinge Conditions. Hinge Conditions are not "propositions which we are convinced of;" instead, they are conditions that we instinctively accept in order to be pragmatic (2006, p. 14). In effect, Hinge Conditions are conditions that must be in place in order for knowledge to be acquired, yet they are not things that we can come to know ourselves.

\section{Dretske's Channel Conditions and Hinge Conditions}

On any form of cursory examination, it is apparent that the notion of Hinge Conditions is similar to Dretske's idea of channel conditions ${ }^{9}$. According to Dretske, in order for subject $\mathrm{S}$ to say that he or she havs knowledge of proposition $\mathrm{p}, \mathrm{S}$ must have a conclusive reason $r$ for $p$; also the following conditions must be met: (1) $r$ is a

\footnotetext{
9 These are conditions that have to be in place in order for there to be any flow of information along communication channels.
} 
conclusive reason for $p$, (2) S believes $p$ on the basis of $r$, and (3) $S$ knows $r$ or $r$ is one of S's experiences. In order for you to fully grasp Dretske's idea of what constitutes knowledge, you must first understand what he means when he uses the term "conclusive reason." For Dretske, $\mathrm{r}$ is a conclusive reason for $\mathrm{p}$ if $\mathrm{r}$ carries the information that p. But, what does it mean to carry information? According to Dretske, $r$ carries the information that $p$ if (1) $r$ is a proposition and $\operatorname{Pr}(p)<1$ while $\operatorname{Pr}(\mathrm{p} \mid \mathrm{r})=1$, or $(2) \mathrm{r}$ is an experience as if $\mathrm{p}$ and $\operatorname{Pr}(\mathrm{p})<1$ while $\operatorname{Pr}(\mathrm{p} \mid \mathrm{S}$ is having $\mathrm{r})=1$. Moreover, in order for Dretske’s system for communicating knowledge (i.e. the communication channel) to work, objective certainties ${ }^{10}$ called channel conditions have to be in place. These channel conditions are not conditions that we are rationally certain of, or have knowledge of, but rather they are background conditions that must be in place in order for any knowledge about the external world to be acquired at all. In other words, channel conditions always have an objective probability of 1 .

If we apply Wittgenstein's idea of language games to Dretske's idea of communication channels, we can more appropriately utilize Wittgenstein's concept of Hinge Propositions. As stated earlier, Hinge Propositions are more aptly termed Hinge Conditions. These Hinge Conditions serve essentially the same function as Dretske's channel conditions (i.e. they are the ground upon which knowledge claims

\footnotetext{
10 It is important to note that the term objective certainty is not being used in the way of the term rational certainty. A rational certainty can be expressed as a personal credence in a proposition. On the other hand, an objective certainty should be thought of as a relative frequency, which is not open to rational interpretation.
} 
can be based on). As such, if the Hinge Conditions were not in place, we would not be able to make any claims of knowledge.

It may be easier to think about Hinge Conditions as specific rules within a language-game that are in place. In order to more clearly illustrate this, let us imagine that a game of chess is taking place. One condition for such a game is that the bishop piece may only move diagonally. If this rule is broken, then the game of chess is no longer being played. The rule is, in a sense, built into the game of chess, and while the rule may change in the future, it is an objective certainty about the game at this moment in time. Language-games work much the same as the game of chess: Hinge Conditions serve as channels, or grounds, for ordinary propositions, and in order for language games to take place, the Hinge Conditions must be serving as the rules for the game. While Hinge Conditions can change over time, the Hinge Conditions that are in place are conditions that always hold.

Hinge Conditions differ from the rules of a chess game in that they are implicit as opposed to explicit. In fact, as stated earlier, Hinge Conditions are not even in the position to be known at all. Rather than rules that one accepts, they are rules that force themselves upon anyone who takes part in a language-game. This interpretation is different than Wittgenstein's original one, as Wittgenstein would have us believe that Hinge Conditions are propositions that should be accepted because of the rules of the language-game. In other words, Hinge Conditions, according to Wittgenstein, are propositions that we should be rationally certain of so that we can abide by the rules of the language-game. However, if we apply 
Dretske's idea of objectively certain conditions (i.e. channel conditions) to Hinge Conditions, combined with Wittgenstein's own idea that our acceptance of Hinge Conditions is in a sense animal or instinctual, rather than rational, then it becomes clear that the Hinge Conditions are not consequences of the rules of the languagegame; rather, they are the rules of the game themselves. And, if the Hinge Conditions are the rules of the language-game, then they are not open to doubt because they are objective certainties.

\section{Conclusion}

Skepticism is a pressing epistemological issue that is unfortunately extremely difficult to circumvent. Fallibilism fails to solve the problem of the Transmissibility Argument for Skepticism by virtue of contradicting itself. Wittgenstein's original portrayal of Hinge Propositions as the answer to skepticism is also flawed. His idea that Hinge Propositions are indubitable propositions runs into the problem of not being clear on how exactly the Hinge Propositions are indubitable. More simply, there is no proof that the doubting of a Hinge Proposition actually causes the doubt itself to lose its meaning. However, if one is willing to give up closure, then the problem of skepticism can be resolved. In order to solve the problem of skepticism, we can conflate Dretske's idea of channel conditions together with the idea that Hinge Propositions are not propositions that we are rationally convinced of but rather things that we appreciate in an animal or instinctual way, and so that we can come to the conclusion of the existence of Hinge Conditions. These conditions act as rules for the language-game, and since the conditions are built into the framework 
of the language-game, they are beyond doubt. So, following the introduction of Hinge Conditions into the language-game, (C) of the Transmissibility Argument can be refuted. And, while (P3) is not proven false, as the Hinge Condition cannot be known, we are able to appreciate the condition in a basic way given that we only implement Hinge Conditions that we find pragmatically beneficial. 


\section{References}

Feldman, Richard. "Skepticism (1)." Epistemology. Upper Saddle River: Pearson Education, 2003. 108-122. Print.

Pritchard, Duncan. "Wittgenstein on Skepticism." Oxford Handbook to Wittgenstein (2006): 3, 14. Print.

Pritchard, Duncan. "Wittgenstein and the Groundlessness of Our Believing." Synthese (2012): 261-62. Print.

Wittgenstein, Ludwig. On Certainty. New York: Harper \& Row, 1969. 44-47. Print. Wittgenstein, Ludwig, G.E.M. Anscombe, P.M.S. Hacker, and J oachim Schulte. Philosophical Investigations. 4th ed. Oxford: Wiley-Blackwell, 2009. 8. Print. 